\title{
Common Cold and Acute Rhinosinusitis: Up-to-Date Management in 2020
}

\author{
Francesca Jaume $^{1} \cdot$ Meritxell Valls-Mateus ${ }^{2} \cdot$ Joaquim Mullol $^{3,4,5}$ \\ Published online: 3 June 2020 \\ (C) Springer Science+Business Media, LLC, part of Springer Nature 2020
}

\begin{abstract}
Purpose of Review The purposes of the review are as follows: (1) to define acute rhinosinusitis (ARS) and their phenotypes, (2) to highlight the ARS management according to international guidelines, (3) to compare the physicians' management with the ARS guideline recommendations, and (4) to report ARS socioeconomic burden.

Recent Findings Bacterial and non-bacterial ARS have similar symptoms, although they can be discriminated by using a combination of specific signs and symptoms. The prescription of antibiotics should be limited to clearly suspected bacterial ARS. There is an overuse of diagnosis tools and treatment prescriptions. The total cost per ARS episode in Europe is over $€ 1000$. Summary ARS is mainly an inflammatory disease triggered by viral infection, and few cases end up developing bacterial infection. In most of the cases, it is a self-resolving disease which diagnosis is mainly clinical and the treatment symptomatic. The incidence of complications is low and independent of antibiotic use. There is a high socioeconomic burden associated to ARS.
\end{abstract}

Keywords Acute rhinosinusitis $\cdot$ Common cold $\cdot$ Respiratory tract infections $\cdot$ Bacterial acute rhinosinusitis $\cdot$ EPOS $\cdot$ Costs

\section{Introduction}

Acute rhinosinusitis (ARS) is an inflammatory disease affecting the nose and paranasal sinuses with duration up to 12 weeks. The main trigger cause is a viral infection (common

This article is part of the Topical Collection on Rhinosinusitis

Francesca Jaume

fjaumemonroig@hotmail.com

Joaquim Mullol

jmullol@ clinic.cat

1 Servei d'Otorrinolaringologia, Hospital Comarcal d'Inca, Carretera Vella de Llubí, 07300 Inca, Illes Balears, Spain

2 Servei d'Otorrinolaringologia, Hospital Universitari Son Espases, Palma, Illes Balears, Spain

3 Unitat de Rinologia i Clínica de l'Olfacte, Servei d'Otorinolaringologia, Hospital Clínic, Universitat de Barcelona, Barcelona, Catalonia, Spain

4 Immunoal.lèrgia Respiratòria Clínica i Experimental, Institut d'Investigacions Biomèdiques August Pi i Sunyer (IDIBAPS), Barcelona, Catalonia, Spain

5 Centro de Investigación Biomédica En Red en Enfermedades Respiratorias (CIBERES), Madrid, Spain cold) that can be prolonged on time (post-viral) and, in a small number of patients, may develop a bacterial infection. It is important to discriminate the different phenotypes of ARS to understand the diagnostic and therapeutic requirements in every individual case $[1 \bullet \bullet]$.

ARS has a significant impact on quality of life [2••], although it usually is a self-resolving disease and the incidence of chronicity or complications is very low. Despite this, both primary care physicians and ENT specialists abuse diagnostic tools and overuse drug prescriptions [3•].

The aim of the present article is to review the incidence of ARS, discuss its etiology (inflammation versus infection), describe ARS different phenotypes, and analyze the recommendations of international guidelines for its management. Furthermore, we will highlight the use and abuse of diagnostic tools and prescribed medications, while exploring the similarities and differences between children and adult disease.

\section{Definition}

According to the European Position Paper on Rhinosinusitis and Nasal Polyps (EPOS) [1••], ARS should be suspected 
when there are two or more nasal symptoms, one of which should be either nasal congestion/blockage/obstruction or rhinorrhea (anterior or post-nasal drip), while the others could be either facial pain/pressure or reduction/loss of smell, lasting up to 12 weeks. In children, ARS should be considered when there are two or more of the following symptoms: nasal blockage/congestion, discolored nasal discharge, and cough.

Although it is important to note that there are other infectious etiologies (bacteria, fungi) of this illness, the most common is caused by viruses. The disease may present in three main clinical phenotypes: viral ARS or common cold when the episode lasts up to 10 days and post-viral ARS when symptoms persist longer than 10 days or worsens after 5 days. Bacterial ARS is defined by the presence of three or more of the following clinical findings: fever $\left(\geq 38^{\circ} \mathrm{C}\right)$, severe local pain, double sickening, unilateral disease (with discolored mucus), or elevation of C-reactive protein (CRP)/erythrocyte sedimentation ratio (ESR) in blood test (Fig. 1) $[1 \bullet \cdot$.

American guidelines (ICAR) note similar definitions and symptoms but stratify to ARS, when symptoms last up to 4 weeks, and sub-acute rhinosinusitis when the duration is between 4 and 12 weeks. Like the European guidelines, they consider viral ARS when the disease duration is less than 10 days $[4 \cdot \bullet]$.

\section{Epidemiology/Incidence of Diseases}

The prevalence of ARS in the general population is variable depending on different studies, noted to be between $6 \%$ and $15 \%[5,6]$. Viral ARS or common cold has a very high incidence, presenting two to five episodes per person a year [7]. In children, this incidence could be up to four times higher [8], with URTIs being one of the main causes of primary care consultations [9•]. Post-viral ARS is less common, with an incidence of about 3 episodes per 100 inhabitants a year [10] in adults (Iceland) with a lower frequency in pediatric populations and differences noted among different age groups (2 cases per 100,000 in $\leq 4$ years old, $4-7$ cases per 100,000 in 5-14 years old, and 18 cases per 100,000 in 15-17 years old) [11]. In a recent study in Germany, the incidence was found to be 18.8 episodes per 1000 inhabitants per year [12••]. Classically, the incidence of bacterial ARS is estimated to be $0.5-2 \%$ of all ARS viral infections, although recent studies have suggested it to be higher. The rate of positive cultures is about $50 \%$ in patients with clinical suspicion of bacterial ARS [13•].

Many predisposing factors for ARS have been described: environmental dampness, anatomical factors (particularly in recurrent ARS episodes [14]), mucocilliary impairment, smoking, as well as anxiety and depression $[1 \bullet \cdot]$. There is also a higher incidence of episodes during the cold months

(POS) Definition of Acute Rhinosinusitis

Increase in symptoms after $\mathbf{5}$ days, or persistent symptoms after 10 days with less than 12 weeks duration

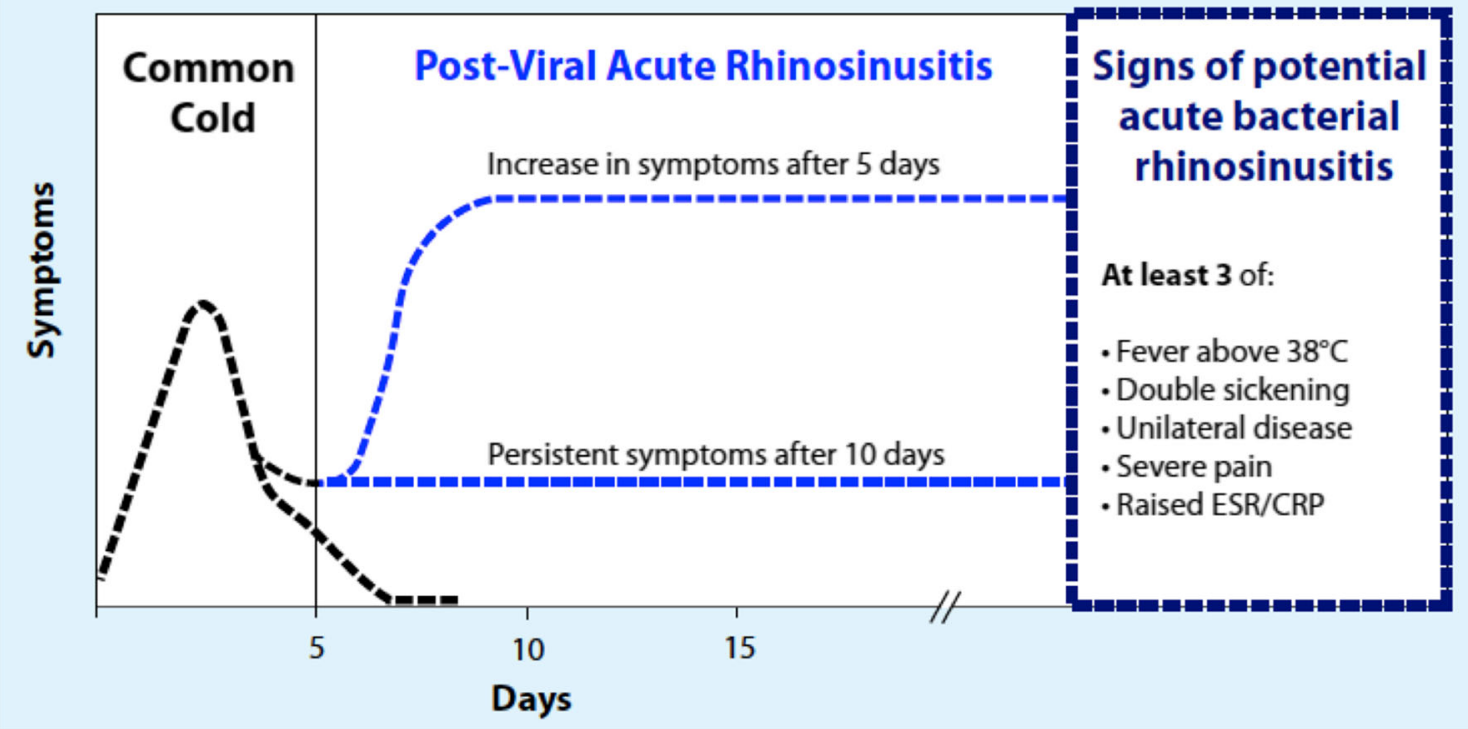

Fig. 1 Definition of ARS phenotype bases on EPOS 2020 Consensus. The duration of symptoms is used to differentiate viral ARS (common cold) from post-viral ARS, which is considered when the symptoms persist longer than 10 days or worsen after 5 days. Bacterial ARS should be suspected at any time when the presence of three or more of the sings or symptoms related to bacterial ARS are found 
(especially in patients with CRS at baseline [15•]). On the other hand, laryngo-pharyngeal reflux was not found to be a clear underlying factor $[1 \bullet \bullet]$.

One of the most interesting and controversial predisposing factors to develop ARS is allergic rhinitis (AR). The incidence of ARS in patients with AR was reported to be 4.4 times higher than in non-allergic rhinitis [16], but other authors have concluded that the presence of allergy in ARS patients might be incidental [17]. A recent study supports however the role of an atopic phenotype as a risk factor to develop ARS in children [18•] while other studies have demonstrated that AR is an insignificant risk factor [19॰]. Since there is a clear difficulty in discriminating an AR exacerbation and ARS, exploring symptoms, such as sneezing, itching, and specific triggers worsening symptoms, which would be indicative of AR, can be quite helpful.

\section{Inflammation Versus Infection}

ARS is mainly an inflammatory disease of the nose and paranasal sinuses. Usually, a viral infection triggers the inflammatory cascade in the context of common cold. In few cases, this inflammatory condition of the mucosa may facilitate a bacterial infection $[1 \bullet \cdot$. As a result, three different ARS phenotypes are described: viral, post-viral, and bacterial ARS. But it should be noted that these entities often overlap, and their symptoms are very similar. Regarding viral ARS, the rhinovirus has been found to be the cause of $50 \%$ of the common cold episodes [20] although other viruses such as adenovirus, coronavirus, influenza virus, and even SARS-CoV-2 virus (responsible for the recent COVID-19 pandemics) could also be involved [21]. Typically, the common cold has a duration of up to 7 to 10 days. When the symptoms persist after the viral disease (over 10 days), the clinical process is called post-viral ARS $[1 \bullet \bullet]$. In a few number of cases $(0.5-2 \%$ of all common colds), this inflammatory condition may lead into a bacterial infection [22].

\section{Children vs Adults}

Although ARS seems to have similar pathophysiology in children and adults, viral ARS incidence is however greater in children, while post-viral ARS incidence is more common in adults $[1 \bullet \cdot$. The symptomatology may also differ. While in adults cough is considered a secondary symptom (except for SARS-CoV-2 virus), in children, it is one of the main common symptoms [23] being strongly considered in the diagnostic protocols $[1 \bullet \bullet, 4 \bullet \bullet]$. On the other hand, posterior rhinorrhea and hyposmia, which are cardinal symptoms in adult, are not in children, likely because it is not easy for the young child to describe or acknowledge them. As in adults, no complementary tests are needed to diagnose ARS and its treatment, if there is no suspicion of bacterial origin or complication, should be strictly symptomatic $[1 \bullet \bullet]$. A detailed description of medical therapy in children and adults is provided later in the treatment section.

\section{Diagnosis}

According to EPOS and American guidelines $[1 \bullet \bullet, 4 \bullet \bullet]$, ARS diagnosis is strictly based on the sudden onset of $\geq 2$ nasal symptoms (nasal congestion/obstruction, rhinorrhea, facial pressure, or loss of smell). This diagnosis may be supported by endoscopic findings (mucosal edema or rhinorrhea), but they are not necessary in a primary care consultation. Although the use of imaging tests is not recommended, except in complicated cases [24••, 25], a clear overuse of diagnostic tools has been found, where physicians recommended plain $\mathrm{X}$-ray or CT scan in $70 \%$ and $22 \%$ of post-viral ARS episodes and even in 55\% and $12 \%$ of viral (common cold) episodes, respectively [3•].

The most difficult issue is to correctly diagnose bacterial ARS (ABRS). Although a rather invasive technique, the gold standard to diagnose ABRS is the antral puncture and culture [26]. The culture of middle meatus secretions obtained under endoscopic visualization has been demonstrated to have similar specificity and sensibility [27 $]$. However, a culture result takes a few days, and is not useful in the acute situation. Some authors have considered the presence of opacification in the sinuses in X-ray or CT can predict a bacterial origin; however, it has been clearly demonstrated that this is not specific for ABRS. As a matter of fact, the majority of patients with common cold present with opacification due to mucous in the paranasal sinuses [28••]. For this reason, recent studies have been trying to find biochemical markers or specific symptoms that could help to differentiate bacterial from non-bacterial ARS. Regarding symptoms, unilateral facial or dental pain has been identified as a good predictor of bacterial ARS [29], but with limited evidence. Dental pain in the superior jaw has been recently identified to be the symptom more strongly related to bacterial ARS [30••]. Classically, the purulence of nasal discharge has also been considered a sign of bacterial infection, but a recent work by Ebell et al. [30・•] has showed however that discolored discharge may be also present in post-viral and even in viral cases, thus invalidating the previous correlation with ABRS. A body temperature $\geq 38^{\circ} \mathrm{C}$ has also been associated with a high risk of bacterial infection [31]. Concerning inflammatory biomarkers, Hansen et al. [31] and Autio et al. [32••], in a recent systematic review, noted that an elevation of C-reactive protein (CRP) and/or erythrocyte sedimentation rate (ESR) support the diagnosis of ABRS, but with poor sensitivity and without being considered a diagnostic marker of the disease. With that said, it does seem 
clear that the presence of low rates of CRP provides evidence against the use of antibiotics [25].

The EPOS consensus $[1 \bullet$ ] recommends the use of a combination of signs and symptoms to determine the probability of bacterial origin and defines ABRS when 3 or more of the following five criteria are present: discolored discharge with unilateral predominance, severe local pain, fever $\geq 38^{\circ} \mathrm{C}$, double sickening, or elevation of CRP/ESR. These EPOS criteria have been demonstrated to have better specificity than IDSA (Infectious Diseases Society of America) criteria for diagnosing bacterial ARS [33•]. The IDSA guideline considers bacterial ARS when there are $\geq 1$ of the following criteria: symptoms lasting for more than 10 days with no improvement, severe symptoms from the onset (fever $\geq 39{ }^{\circ} \mathrm{C}$ or discolored discharge from the beginning and during 3-4 days), or double sickening after 5-6 days [34].

To summarize, in normal situations (apart from virus epidemics or pandemics), there is no need for complementary diagnostic tools to diagnose viral or post-viral ARS, while a blood test to determine CRP/ESR may be helpful when ABRS is suspected.

\section{Treatment}

The first step in common cold and ARS management is the prevention of viral infection mainly reinforcing the use of hygiene rules such as hand washing. In special epidemic situations, such as the 2020 COVID-19 pandemics, more strict recommendations such as social distancing, facemask and eye guards, as well as home confinement may be required [35].

The updated management of viral (common cold) and postviral ARS, and ABRS according to EPOS2020, is summarized in Table 1. The highlights for medical therapy, according to phenotypes and different guidelines $[1 \bullet \bullet, 4 \bullet \bullet$, include the following:

\section{Common cold:}

- Recommended therapy (mainly symptomatic): paracetamol; non-steroidal anti-inflammatory drugs (NSAIDs); second-generation antihistamines with short-term benefit in reducing symptoms the first 2 days [36•]; nasal decongestants with small effect in nasal congestion in adults [37]; combination of analgesics and nasal decongestants [38]; ipratropium bromide for reducing rhinorrhea [39]; probiotics; zinc when administered the first $24 \mathrm{~h}$ after the onset of symptoms [40, 41•]; nasal saline irrigations [42]; vitamin $C$, in selected patients with suspected deficit or with high levels of physical activity [43]; and some herbal medicines (BNO 1016, cineole, and Andrographis paniculata SHA-10) [1••].
- Not recommended therapy: antibiotics [44], intranasal corticosteroids (INCS) [45], heated humidified air [46•], echinea products [47], homeopathy products $[48 \cdot]$.

- Preventive therapy recommended: probiotics, with slight benefit but low-quality evidence [49], practice of moderate and regular exercise [50].

\section{Postviral ARS:}

- Recommended therapy: symptomatic treatment; INCS, although the beneficial effect in symptoms is clear, as ARS is a self-limited disease, consider the need of their use depending on the severity of symptoms [1••]; sinfrontal, a homeopathy product with slight benefit but low evidence [51]; and some herbal compounds such as Cyclamen europaeum, which improves some symptoms but with low evidence [52], Pelagorium sidoides [53], and BNO 1016, mainly for nasal congestion [54].

- Not recommended therapy: antibiotics, neither in children nor adults; systemic corticosteroids; nasal decongestants; second-generation antihistamines $[1 \bullet \bullet, 4 \bullet \bullet]$.

\section{Bacterial ARS:}

- Recommended therapy: symptomatic treatment and antibiotics, especially amoxicillin/penicillin (betalactams) are effective in adult patients with signs and symptoms of ABRS; data is very limited in children, demonstrating lack of efficacy compared with placebo, but with more adverse events [1••]. Sodium hyaluronate plus saline solution may have and additive effect to antibiotics [55•]. Oral corticosteroids added to antibiotics have shown a moderate effect reducing facial pain. Currently, there is a need for quality research in ABRS on the full range of medications and in particular, topical and oral corticosteroids, antihistamines, decongestants, and saline and steam inhalation $[1 \bullet \bullet]$.

The challenge in discriminating bacterial from nonbacterial ARS often leads to an over-diagnosis of ABRS, which result in an overuse of diagnostic testing and early unnecessary prescription of antibiotics. In a study from the UK, $88 \%$ of the consultations for rhinosinusitis resulted in antibiotic prescription, while only $11 \%$ were deemed appropriate $[56 \bullet \bullet$. The same was true in the Netherlands where $34 \%$ of the interviewed primary care physicians chose an antibiotic as treatment for a patient with moderate severe acute rhinosinusitis [57]. In a study from Spain, even when ABRS 
Table 1 Acute rhinosinusitis treatment and recommendations for both adults and children based slightly modified from EPOS2020 (Fokkens 2020)

\begin{tabular}{|c|c|c|c|}
\hline & Acute viral rhinosinusitis (common cold) & Acute post-viral rhinosinusitis & Acute bacterial rhinosinusitis \\
\hline Antibiotics & $\begin{array}{l}\text { Recommendation against (1a -) } \\
\text { in children and adults }\end{array}$ & $\begin{array}{l}\text { Recommendation against (1a -) } \\
\text { in children and adults }\end{array}$ & $\begin{array}{l}\text { Careful patient selection to } \\
\text { avoid unnecessary use. } \\
\text { Recommendation in adults } \\
(1 \mathrm{a})^{\mathrm{a}} \\
\text { No recommendation in } \\
\quad \text { children }(1 \mathrm{a}-)\end{array}$ \\
\hline $\begin{array}{l}\text { Nasal } \\
\text { corticoste- } \\
\text { roids }\end{array}$ & Recommendation against (1a -) & $\begin{array}{l}\text { Are effective reducing the symptoms, but as a } \\
\text { self-limiting disease they are optional in } \\
\text { adults (1a) } \\
\text { No advise can be made in children (low quality } \\
\text { of evidence) }\end{array}$ & No studies \\
\hline $\begin{array}{l}\text { Systemic } \\
\text { corticoste- } \\
\text { roids }\end{array}$ & No studies & Recommendation against (1a -) in adults & Insufficient data ${ }^{\mathrm{b}}$ \\
\hline Antihistamines & $\begin{array}{l}\text { Short-term beneficial effect the overall symptoms in } \\
\text { adults (1a) }\end{array}$ & $\begin{array}{l}\text { Low quality of evidence studies, no additive } \\
\text { beneficial effect in studies in adults and } \\
\text { children }\end{array}$ & $\begin{array}{l}\text { Low quality of evidence } \\
\text { studies, no additive } \\
\text { beneficial effect in studies } \\
\text { in adults and children }\end{array}$ \\
\hline $\begin{array}{l}\text { Nasal } \\
\text { deconges- } \\
\text { tants }\end{array}$ & $\begin{array}{l}\text { Multiple doses may have a small positive effect on } \\
\text { nasal congestion in adults (1a) without increase } \\
\text { the risk of adverse events }\end{array}$ & $\begin{array}{l}\text { May be effective in improving mucociliary } \\
\text { clearance in the acute phase. Absence of } \\
\text { clinically relevant data }\end{array}$ & Insufficient data \\
\hline $\begin{array}{l}\text { Antihistamine + } \\
\text { nasal } \\
\text { decongestant } \\
+ \text { analgesic }\end{array}$ & $\begin{array}{l}\text { Some general benefit in adults and older children } \\
\text { with common cold (1a). No evidence in young } \\
\text { children }\end{array}$ & Insufficient data & No studies \\
\hline $\begin{array}{l}\text { Ipratropium } \\
\text { bromide }\end{array}$ & $\begin{array}{l}\text { Improves rhinorrea but has no effect on nasal } \\
\text { obstruction (1a) }\end{array}$ & Insufficient data & Insufficient data \\
\hline Saline irrigation & Slight benefits decreasing the symptoms of URTIs & $\begin{array}{l}\text { Very low quality of evidence, but it may be } \\
\text { beneficial in adults (1b) }\end{array}$ & $\begin{array}{l}\text { Insufficient data. No advice } \\
\text { can be given about the use } \\
\text { of nasal saline irrigation }\end{array}$ \\
\hline Zinc & $\begin{array}{l}\text { Acetate or gluconate } \geq 75 \mathrm{mg} / \text { day when taken } \\
\text { within } 24 \mathrm{~h} \text { of onset of symptoms reduces the } \\
\text { duration of common cold (1a) }\end{array}$ & No studies & No studies \\
\hline $\begin{array}{l}\text { Herbal } \\
\text { medicines }\end{array}$ & $\begin{array}{l}\text { BNO1016, cineole and Andrographis paniculata } \\
\text { SHA-10 extract have significant impact on } \\
\text { symptoms of common cold without important } \\
\text { adverse events (1b). } \\
\text { Echinacea is not reccomended (1a -) }\end{array}$ & $\begin{array}{l}\text { In adults, BNO1016 tablets and Pelargonium } \\
\text { sidoides drops and Myrtol (and other } \\
\text { essential oil) capsules have significant impact } \\
\text { on symptoms (1b) }\end{array}$ & Insufficient data \\
\hline
\end{tabular}

BNO1016 (Sinupret) is an extract of five herbal drugs (gentian root, prímula flower, sorrel herb, elder flower, and verbena herb). 1a: Systematic review (with homogeneity) of RCTs. 1b: Individual RCT (with narrow confidence intervals)

URTI upper respiratory tract infection

${ }^{a}$ From the limited data available, it seems that especially beta-lactams (amoxicillin/penicillin) are effective and moxifloxacin (fluoroquinone) is not. The efficacy of beta-lactams is evident at day 3 where patients already experience better symptom improvement and continue with a higher number of cures at completion of treatmen

${ }^{\mathrm{b}}$ In ABRS, a short curse of oral corticosteroids (3-5 days) can be prescribed if severe unilateral pain is present

${ }^{\mathrm{c}}$ Second-generation antihistamines could be prescribed for the treatment of concomitant allergic rhinitis

patients were excluded, the use of antibiotics was found to be around $60 \%$ in patients with common cold and $70 \%$ in those with post-viral ARS [3•]. The American Rhinosinusitis guidelines highlight the fact that although effective in adults, the actual benefit of antibiotics is small, needing to treat between 11 and 15 patients to get 1 individual to improve [4*•]. The overuse of antibiotics has also been associated with an increment of antibiotic resistance, which is directly related to increased morbidity and mortality due to resistant bacterial infections [58, 59॰]. So, once again, in spite of the clinical suspicion of ABRS, the decision to treat a patient with antibiotics should be made on an individual basis. In order to help to decrease the inappropriate use of antibiotics for ARS, published studies emphasize the importance of physician communication skills on the use of antibiotics, responsible justification, and peer comparison and training of physicians, to help 
patients understand the downside to inappropriate prescriptions $[1 \cdot \bullet]$.

Besides antibiotics, other medications such as antihistamines and mucolytic have not shown any benefit in treating post-viral. Despite this, many physicians continue to prescribe these agents regularly $(\sim 50 \%)$ as reported in several studies from Spain [3•], France [60], or Asia [6].

\section{Complications}

The incidence of ABRS complications has been shown to be approximately 3:1,000,000 per year despite the different utilization of antibiotics in the various countries $[1 \bullet \bullet$. Specifically, it has been demonstrated that the use of antibiotics does not prevent complications [61•]. Complications of ABRS are typically classified as orbital (60-80\%), intracranial (15-20\%), and rarely osseous (5\%) [1・•]. Orbital complications, the most commonly related to ABRS, are a consequence (in decreasing frequency) of ethmoid, maxillary, frontal, and rarely the sphenoid sinusitis [62]. Orbital complications commonly affect children $[63 \bullet, 64 \cdot]$, a population that is known to express fewer clinical signs and symptoms, and thus, it is important to have a high level of clinical suspicion.

According to EPOS recommendations, one should rule out a complication when a patient presents with one or more of the following signs and/or symptoms: periorbital edema/erythema, displaced globe, double vision, ophtalmoplegia, reduced visual acuity, severe headache, frontal swelling, signs of sepsis, or other neurological signs $[1 \bullet \bullet$.

Regarding diagnosis of complications, the accuracy of a clinical diagnosis is estimated to be around $82 \%$ and the accuracy of CT $91 \%$ [65]. MRI is, however, considered the "gold standard," as it is more sensitive than CT scan. When available, MRI should be the imaging modality of choice, having the additional diagnostic value to exclude or confirm cavernous sinus thrombosis and soft tissue involvement $[66$, 67].

According to EPOS guidelines, the main indications for surgical intervention in orbital complications of ABRS are evidence of subperiosteal or intraorbital abscess in CT scan or MRI (exception for small volume abscesses). Subperiosteal abscess in children is not an absolute indication for immediate surgical intervention. Conservative measures can be safe and effective if appropriately used. A reduced visual acuity, loss of color vision, affected afferent pupillary reflex, or inability to assess vision, however, are indications for urgent surgery. When conservative treatment is chosen, progression or no improvement in orbital signs (diplopia, ophthalmoplegia, proptosis, swelling, chemosis) or in the general condition (fever, infection parameters), after $48 \mathrm{~h}$ of intravenous antibiotic treatment is also an indicator of the need for emergency surgery $[1 \bullet \bullet$.
Endocranial complications of ABRS are usually associated with fronto-ethmoidal or sphenoid rhinosinusitis [68] and include epidural or subdural empyema, brain abscess, meningitis, cerebritis, and superior sagittal and cavernous sinus thrombosis. They may present with specific central nervous system signs, such as nausea and/or vomiting, neck stiffness, and altered mental stat, or non-specific symptoms and signs (high fever, headache, reduced consciousness), or can even be silent [69]. The pathogens most commonly isolated are Streptococcus and Staphylococcus species including methicillin-resistant (MRSA) and anaerobes [70]. The recommended treatment involves neurosurgical drainage procedures and endoscopic drainage of the paranasal sinuses (most often the frontal sinus) $[71 \bullet]$.

\section{Societal Burden and Socioeconomic Costs}

Despite the fact that ARS is usually a self-limited, with low risk of further morbidity, it presents a considerable burden to public health [4••], being an important cause of work absenteeism [72]. As reported above, a significant overuse of diagnostic tests and medications has been reported in multiple countries $[3 \cdot, 6,57]$, with very few studies addressing the economic impact of ARS. In the 1990s, the cost of ARS reached US $\$ 3390$ million per year in the USA [73]. In Europe, a total cost of $\sim € 1100$ per ARS episode was recently examined, with the major cost $(75 \%)$ attributable to indirect costs $[2 \cdot \bullet]$. Recent data from Spain demonstrated that direct costs of ARS where greater in postviral $(\sim € 440)$ than viral ( $€ 320)$ ARS episodes, and not surprisingly, severe cases resulted in greater direct cost [74], with the main driver of direct cost attributable to medical visits $[72,74]$. As the economic costs are quite large, there is a clear unmet need with further research needed to optimize appropriate testing and therapy. Concerning medical visits, health education should be improved and encouraged, teaching the public that ARS is a self-limited and non-complicated disease, which usually only requires symptomatic treatment, while medical consultations should be restricted to severe or complicated cases. On the other hand, decreasing the costs related to diagnosis and treatment are directly linked to medical management. Svensson et al. showed that the cost of treating ARS with topical corticosteroid was much lower compared with the use of amoxicillin [75]. Regarding the costs related to antibiotic use, Cramer et al. reported a dramatic decrease in costs when $t$ guideline recommendations were followed, compared with when they were not (US\$352 vs. US\$166 million per year) [76••]. Therefore, knowledge of up-to-date guidelines and scientific recommendations is strongly recommended for both primary care physicians and specialists in order to avoid the overuse of diagnostic tools and prescription of unnecessary 
medications, especially antibiotics, in the management of ARS [77•].

\section{Conclusions}

- The first and most important rule for common cold and ARS management is the prevention of viral infection through hygiene behavior such as hand washing. In special epidemic situations such as the 2020 COVID-19 pandemics, more strict recommendations such as social distance and home confinement may be required.

- Post-viral ARS is mainly an inflammatory disease, which usually begins as a viral infection (common cold, URTI, or viral ARS), but may persist longer than 7-10 days or worsen after 5 days. Some rare cases (less than 2\%) may develop bacterial ARS.

- The incidence of viral ARS is very high (2-5 episodes/ person/year) while post-viral ARS has an incidence about 3 episodes per 100 people a year.

- The most common ARS symptoms are nasal blockage or congestion and anterior or posterior rhinorrhea. In adults, facial pain or pressure and loss of smell are also cardinal symptoms, while in children, cough is more relevant.

- The diagnosis is clinical, based on the sudden onset of nasal symptoms (nasal blockage/obstruction, nasal discharge/rhinorrhea, hyposmia, and facial pain/pressure), and there is no need for complementary tests.

- The distinction between bacterial and non-bacterial ARS remains a diagnostic challenge. The presence of a fever, unilateral focality, local pain, and elevation of CPR/ERS seems to be the best way to predict bacterial ARS.

- In special situations, such as the 2020 COVID-19 pandemics, a sudden severe loss of smell (anosmia), even with the absence of other nasal or general symptoms (dry cough, fever), should be considered a symptom of suspicion while the definitive diagnosis should be specific by using a PCR test for the SARS-Cov-2 virus.

- Viral ARS treatment should be symptomatic (analgesic, NSAIDs). Some herbal compounds or minerals like zinc may also help.

- Intranasal corticoids have proven to be useful in post-viral ARS, but, being a self-resolving disease, its use should be individualized. Antibiotics, mucolytic, and antihistamines have not demonstrated any benefit in patients with postviral ARS.

- Antibiotics have only shown some effect in bacterial ARS, although there is a high rate of resolution even without their use. Therefore, individual considerations, taking into account the adverse effects and increased drug resistances, have to be made before prescribing antibiotics.

- Complications are very uncommon, and their incidence is not dependent on the antibiotic use. Orbital complications are common in children while intracranial complications are less frequent. The presence of ophthalmological or neurological symptoms should raise the suspicion of a complication and imaging tests should be obtained. Therapeutic management of ARS complications includes hospital admission and intravenous antibiotics and often requires surgery (ORL and/or neurosurgery).

- The economic burden of ARS is incredibly high due to the large number of medical visits, the misuse of diagnostic testing, and the overuse of medications, as well as for the high indirect costs. Disseminating the concept of ARS being a mild and self-resolving disease among patients and physicians remains an unmet need that is required to reduce the high costs of this illness.

\section{References}

Papers of particular interest, published recently, have been highlighted as:

- Of importance

- Of major importance

1.• Fokkens W, Lund V, Hopkins HP, Kern R, Reitsma S, et al. EPOS2020: European Position Paper on Rhinosinusitis and Nasal Polyps 2020. Rhinology. 2020;58(Suppl S29):1-464 The 2020 Updated European position paper on Rhinosinusitis and nasal polyps is performing an extended up-to-date, a clear evidencebased recommendations and integrated care pathways in ARS and CRS. It has been the basis for this review article.

2.• Stjärne P, Odebäck P, Ställberg B, Lundberg J, Olsson P. High costs and burden of illness in acute rhinosinusitis: real-life treatment patterns and outcomes in Swedish primary care. Primary Care Resp Journal. 2012;21:174-9 It is the first study on the ARS costs in Europe. Total cost for an ARS episode was 10,260 SEK (€1, 102), 755 of which was related to indirect costs.

3. Jaume F, Quintó L, Alobid I, Mullol J. Overuse of diagnostic tools and medications in acute rhinosinusitis in Spain: a population-based study (the PROSINUS study). BMJ Open. 2018;8(1):e018788 By excluding bacterial ARS, this article shows a significant abuse of diagnostic tools and overuse of medications, predominantly oral antibiotics, by PCPs and ORLs, for both viral and postviral ARS, in Spain.

4.• Orlandi RR, Kingdom TT, Hwang PH, Smith TL, Alt JA, Baroody FM, et al. International Consensus Statement on Allergy and Rhinology: Rhinosinusitis. Int Forum Allergy Rhinol. 2016;6(Suppl 1):S22-S209 This international guideline, mainly from American authors, also reviewed the literature on acute and chronic rhinosinuistis topics, providing evidence-based recommendations for medical and surgical treatment.

5. Fokkens WJ, Lund VJ, Mullol J, Bachert C, Alobid I, Baroody F, et al. European position paper on rhinosinusitis and nasal polyps 2012. Rhinol Suppl. 2012;23:1-298.

6. Wang DY, Wardani RS, Singh K, Thanaviratananich S, Vicente G, $\mathrm{Xu} \mathrm{G}$, et al. A survey on the management of acute rhinosinusitis among Asian physicians. Rhinology. 2011;49(3):264-71.

7. Turner RB. Epidemiology, pathogenesis and treatment of the common cold. Ann Allergy Asthma Immunol. 1997;78:531-40. 
8. Bachert C, Hormann K, Mosges R, Rasp G, Riechelmann H, Müller R, et al. An update on the diagnosis and treatment of sinusitis and nasal polyposis. Allergy. 2003;58:176-91.

9. Finley CR, Chan DS, Garrison S, Korownyk C, Kolber MR, Campbell S, et al. What are the most common conditions in primary care? Systematic review. Can Fam Physician. 2018;64:832-40 This article contains data from 12 countries across 5 continents, and describes the most common clinician-reported conditions in primary care, being respiratory tract infection in the top ten.

10. Oskarsson JP, Halldorsson S. An evaluation of diagnosis and treatment of acute sinusitis at three healthcare centers. Laeknabladid. 2010;96:531-5.

11. Uijen JH, Bindels PJ, Schellevis FG, van der Wouden JC. ENT problems in Dutch children: trends in incidence rates, antibiotic prescribing and referrals 2002-2008. Scand J Prim Health Care. 2011;29:75-9.

12.• Hoffmans R, Wagemakers A, van Drunen C, Hellings P, Fokkens $\mathrm{W}$. Acute and chronic rhinosinusitis and allergic rhinitis in relation to comorbidity, ethnicity and environment. PloS one. 2018;13: e0192330 This is the more recent study talking about ARS prevalence. Using a questionnaire sent to a random sample of the Dutch population $(>\mathbf{8 , 0 0 0}), \mathbf{1 8 \%}$ met the criteria for ARS.

13. Smith SS, Ference EH, Evans CT, Tan BK, Kern RC, Chandra RK. The prevalence of bacterial infection in acute rhinosinusitis: a systematic review and metaanalysis. Laryngoscope. 2015;125:57-69 This study assess the prevalence of bacterial ARS. Their findings suggest than a half of patients with clinical or radiological suspicion of bacterial ARS have a positive bacterial cultures from antral swap or middle meatus sampling.

14. Loftus PA, Lin J, Tabaee A. Anatomic variants of the paranasal sinuses in patients with recurrent acute rhinosinusitis. Int Forum Allergy Rhinol. 2016;6:328-33.

15. Kuiper JR, Hirsch AG, Bandeen-Roche K, Tan BK, Schleimer RP, Kern RC, et al. Prevalence, severity, and risk factors for acute exacerbations of nasal and sinus symptoms by chronic rhinosinusitis status. Allergy. 2018;73:1244-53 This paper analyzes the factors that exacerbate nasal symptoms in patients with CRS, being winter season one of them.

16. Schatz M, Zeiger RS, Chen W, Yang S-J, Corrao MA, Quinn VP. The burden of rhinitis in a managed care organization. Ann Allergy Asthma Immunol. 2008;101:240-7.

17. Pant H, Ferguson BJ, Macardle PJ. The role of allergy in rhinosinusitis. Curr Opin Otolaryngol Head Neck Surg. 2009;17: 232-8.

18. Lin SW, Wang SK, Lu MC, Wang CL, Koo M. Acute rhinosinusitis among pediatric patients with allergic rhinitis: a nationwide, population-based cohort study. PLoS One. 2019;14(2): e0211547 This cohort study compares the incidence of ARS in children with and without allergic rhinitis, and showed that allergic rhinitis was significantly associated with a higher risk of acute rhinosinusitis among pediatric patients.

19. Leo G, Incorvaia C, Cazzavillan A, Consonni D, Zuccotti GV. Could seasonal allergy be a risk factor for acute rhinosinusitis in children? J Laryngol Otol. 2018;132(2):150-3 The authors compared the incidence of ARS, confirmed endoscopically, in a cohort of allergic patients compared to non-allergic patients and reported a comparable incidence.

20. Heikkinen T, Järvinen A. The common cold. Lancet. 2003;361(9351):51-9.

21. Zou L, Ruan F, Huang M, Liang L, Huang H, Hong Z, et al. SARSCoV-2 viral load in upper respiratory specimens of infected patients. N Engl J Med. 2020;382(12):1177-9.

22. Benninger MS, Senior BA. The development of the rhinosinusitis disability index. Arch Otolaryngol Head Neck Surg. 1997;123: 1175-9.
23. Shaikh N, Hoberman A, Kearney DH, Colborn DK, Kurs-Lasky M, Jeong JH, et al. Signs and symptoms that differentiate acute sinusitis from viral upper respiratory tract infection. Pediatr Infect Dis J. 2013:32:1061-5.

24.• Scadding G, Hellings P, Alobid I, Bachert C, Fokkens W, van Wijk $\mathrm{RG}$, et al. Diagnostic tools in rhinology EAACI position paper. Clin Transl Allergy. 2011;1(1):2 This is an European position paper analyzing the need of different diagnostic tools in different nose and sinuses diseases. They conclude that there is no need of complementary diagnostic tools to diagnose ARS.

25. Ebell MH, McKay B, Guilbault R, Ermias Y. Diagnosis of acute rhinosinusitis in primary care: a systematic review of test accuracy. Br J Gen Pract. 2016;66:e612-32.

26. Benninger MS, Appelbaum PC, Denneny JC, Osguthorpe DJ, Stankiewicz JA. Maxillary sinus puncture and culture in the diagnosis of acute rhinosinusitis: the case for pursuing alternative culture methods. Otolaryngol Head Neck Surg. 2002;127:7-12.

27. Benninger MS, Payne SC, Ferguson BJ, Hadley JA, Ahmad N. Endoscopically directed middle meatal cultures versus maxillary sinus taps in acute bacterial maxillary rhinosinusitis: a meta-analysis. Otolaryngol Head Neck Surg. 2006;134:3-9 Being the antral puncture culture the gold standard to diagnose bacterial ARS, this study shows that endoscopically directed middle meatal cultures are very sensitive and provide good accuracy to diagnose bacterial ARS, being more easily obtained than antral cultures, with similar results.

28.• Gwaltney JM, Phillips CD, Miller RD, Riker DK. Computed tomographic study of the common cold. N Engl J Med. 1994;330:25-30 Very important study which shows a high prevalence of CT sinusal occupation in common cold patients, including occlusion and abnormalities in the sinus cavities. These findings are against the use of imaging in non-complicated ARS.

29. Berg O, Carenfelt C. Analysis of symptoms and clinical signs in the maxillary sinus empyema. Acta Otolaryngol. 1988;105:343-9.

30.• Ebell MH, McKay B, Dale A, Guilbault R, Ermias Y. Accuracy of signs and symptoms for the diagnosis of acute rhinosinusitis and acute bacterial rhinosinusitis. Ann Fam Med. 2019;17:164-72 In this study the authors look for predictors of bacterial ARS (confirmed by culture) at different previous studies. Cacosmia and pain in the teeth resulted to the best predictors of ABRS. On the other hand the use of $\mathrm{C}$-reactive protein levels is promising but requires prospective validation.

31. Hansen JG, Hojbjerg T, Rosborg J. Symptoms and signs in cultureproven acute maxillary sinusitis in a general practice population. APMIS. 2009;117:724-9.

32.• Autio TJ, Koskenkorva T, Leino TK, Koivunen P, Alho OP. Longitudinal analysis of inflammatory biomarkers during acute rhinosinusitis. Laryngoscope. 2017;127(2):E55-61 The authors analyzed the blood test results from 50 patients with ARS and conclude that elevated hs-CRP supports the diagnosis of bacterial ARS.

33. Seresirikachorn K, Snidvongs K, Chitsuthipakorn W, et al. EPOS2012 has better specificity com-pared to IDSA2012 for diagnosing acute bacterial rhinosinusitis. Rhinology. 2018;56:241-4 In this article, patients with clinical criteria of bacterial ARS following EPOS2012 and IDSA2012 guidelines were included. Using endoscopic directed middle meatal culture it was showed that both EPOS2012 and IDSA2012 recommendations had modest accuracy, with better specificity for EPOS2012 compared to IDSA2012. This findings suggest that IDSA2012 diagnostic criteria may contribute to inappropriate use of antibiotics.

34. Chow AW, Benninger MS, Brook I, Brozek JL, Goldstein EJ, Hicks LA, et al. IDSA clinical practice guideline for acute bacterial rhinosinusitis in children and adults. Clin Infect Dis. 2012;54:e72 e112. 
35. Lotfinejad N, Peters A, Pittet D. Hand hygiene and the novel coronavirus pandemic: the role of healthcare workers. J Hosp Infect. 2020.

36. De Sutter AI, Saraswat A, van Driel ML. Antihistamines for the common cold. Cochrane Database Syst Rev. 2015:CD009345 This systematic review stated that antihistamines have a limited but significant short-term (days one and two of treatment), but not in the mid to long-term, beneficial effect on the severity of overall symptoms for common cold in adults.

37. Deckx L, De Sutter AI, Guo L, Mir NA, van Driel ML. Nasal decongestants in monotherapy for the common cold. Cochrane Database Syst Rev. 2016;10:CD009612.

38. De Sutter AI, van Driel ML, Kumar AA, Lesslar O, Skrt A. Oral antihistamine-decongestant-analgesic combinations for the common cold. Cochrane Database Syst Rev. 2012:CD004976.

39. AlBalawi ZH, Othman SS, Alfaleh K. Intranasal ipratropium bromide for the common cold. Cochrane Database Syst Rev. 2013;6: CD008231.

40. Singh M, Das RR. Zinc for the common cold. Cochrane Database Syst Rev. 2011;2013:CD001364.

41. Hemila H, Fitzgerald JT, Petrus EJ, Prasad A. Zinc acetate lozenges may improve the recovery rate of common cold patients: an individual patient data meta-analysis. Open Forum Infect Dis. 2017;4: ofx 059 This study shows the efficacy of zinc acetate in common cold, when patients take it within the first 24 hours of onset of symptoms.

42. King D, Mitchell B, Williams CP, Spurling GK. Saline nasal irrigation for acute upper respiratory tract infections. Cochrane Database Syst Rev. 2015:CD006821

43. Hemila $\mathrm{H}$, Chalker E. Vitamin $\mathrm{C}$ for preventing and treating the common cold. Cochrane Database Syst Rev. 2013:CD000980.

44. Kenealy T, Arroll B. Antibiotics for the common cold and acute purulent rhinitis. Cochrane Database Syst Rev. 2013:CD000247.

45. Hayward G, Thompson MJ, Perera R, Del Mar CB, Glasziou PP, Heneghan CJ. Corticosteroids for the common cold. Cochrane Database Syst Rev. 2015;10:CD008116.

46. Singh M, Singh M, Jaiswal N, Chauhan A. Heated, humidified air for the common cold. Cochrane Database Syst Rev. 2017;8(8): CD001728 This recent Cochrane review advice against the use of heated, humidified air for the common cold.

47. Karsch-Volk M, Barrett B, Kiefer D, Bauer R, ArdjomandWoelkart K, Linde K. Echinacea for preventing and treating the common cold. Cochrane Database Syst Rev. 2014:CD000530.

48. Hawke K, van Driel ML, Buffington BJ, McGuire TM, King D. Homeopathic medicinal products for preventing and treating acute respiratory tract infections in children. Cochrane Database Syst Rev. 2018;4:CD005974 In this Cochrane review the authors found no evidence to support the efficacy of homeopathic medicinal products for ARTIs in children.

49. Quick M. Cochrane commentary: probiotics for prevention of acute upper respiratory infection. Explore (NY). 2015;11(5):418-20.

50. Lee HK, Hwang IH, Kim SY, Pyo SY. The effect of exercise on prevention of the common cold: a meta-analysis of randomized controlled trial studies. Kor J Fam Med. 2014;35:119-26.

51. Zabolotnyi DI, Kneis KC, Richardson A, Rettenberger R, Heger M, Kaszkin-Bettag M, et al. Efficacy of a complex homeopathic medication (Sinfrontal) in patients with acute maxillary sinusitis: a prospective, randomized, double-blind, placebo-controlled, multicenter clinical trial. Explore (NY). 2007;3(2):98-109.

52. Pfaar O, Mullol J, Anders C, Hormann K, Klimek L. Cyclamen europaeum nasal spray, a novel phytotherapeutic product for the management of acute rhinosinusitis: a randomized double-blind, placebo-controlled trial. Rhinology. 2012;50:37-44.

53. Timmer A, Gunther J, Rucker G, Motschall E, Antes G, Kern WV. Pelargonium sidoides extract for acute respiratory tract infections. Cochrane Database Syst Rev. 2008:CD006323.
54. Neubauer N, März RW. Placebo-controlled, randomized doubleblind clinical trial with Sinupret sugar coated tablets on the basis of a therapy with antibiotics and decongestant nasal drops in acute sinusitis. Phytomedicine. 1994;1:177-81.

55. Ciofalo A, de Vincentiis M, Zambetti G, et al. Olfactory dysfunction in acute rhinosinusitis: intranasal sodium hyaluronate as adjuvant treatment. Eur Arch Otorhinolaryngol. 2017;274:803-8 In this work, patients with bacterial ARS were randomized in two groups both using antibiotics, steroids, and nasal saline but in the study group, sodium hyaluronate was added to nasal saline solution. Symptom VAS showed statistically significant differences between the two groups, in particular for smell, nasal obstruction and for nasal discharge.

56.• Pouwels KB, FCK D, DRM S, Robotham JV, Smieszek T. Actual versus 'ideal' antibiotic prescribing for common conditions in English primary care. J Antimicrob Chemother. 2018;73:19-26 In this study, the proportions of consultations, concentrated on acute presentations in patients without relevant comorbidities, resulting in an antibiotic prescription were established. The prescribing proportions were then compared with previously established 'ideal' proportions by condition. For rhinosinusitis, a huge difference between real ( $88 \%$ of cases) vs ideal $(11 \%)$ prescriptions was found, identifying a substantial over-prescription of antibiotics in English primary care.

57. Hoffmans R, Schermer T, van Weel C, Fokkens W. Management of rhinosinusitis in Dutch general practice. Prim Care Respir J. 2011;20:64-70.

58. de Kraker ME, Davey PG, Grundmann H, BURDEN study group. Mortality and hospital stay associated with resistant Staphylococcus aureus and Escherichia coli bacteremia: estimating the burden of antibiotic resistance in Europe. PLoS Med. 2011;8:e1001104.

59. Carter D, Charlett A, Conti S, Robotham JV, Johnson AP, Livermore DM, et al. A risk assessment of antibiotic pan-drugresistance in the UK: Bayesian analysis of an expert elicitation study. Antibiotics. 2017;6:9 This study analyzed the effect of drug resistant Gram-negative bacteria in the UK. Over a period of 20 years, cumulative estimates indicate 284,000 cases of resistant Gram-negative bacteremia, this leading to an estimated 79,000 deaths.

60. Klossek JM, Mesbah K. Presentation and treatment of acute maxillary sinusitis in general practice: a French observational study. Rhinology. 2011;49(1):84-9.

61. Hansen FS, Hoffmans R, Georgalas C, Fokkens WJ. Complications of acute rhinosinusitis in The Netherlands. Fam Pract. 2012;29(2): $147-53$ This is a retrospective cohort study among patients hospitalized due to ARS complication, where the use or not of antibiotics previous admission was recorded. They concluded that antibiotic treatment of ARS in general practice does not play a role in preventing complications.

62. Chandler JR, Langenbrunner DJ, Stevens ER. The pathogenesis of orbital complications in acute sinusitis. Laryngoscope. 1970;80: 1414-28.

63. El Mograbi A, Ritter A, Najjar E, Soudry E. Orbital complications of rhinosinusitis in the adult population: analysis of cases presenting to a tertiary medical center over a 13 -year period. Ann Otol Rhinol Laryngol. 2019;128:563-8 This is a retrospective study analyzing patients with ARS complications. The main findings were: $1^{\text {st }}$ ) CRS is very common in adults with orbital complications of rhinosinusitis, with previous sinus surgery and orbital wall dehiscence being noticeably common; $2^{\text {nd }}$ ) older patients are at risk for more severe complications; and $3^{\text {rd }}$ ) conservative treatment suffices in patients with pre-septal and orbital cellulitis.

64. Schollin Ask L, Hultman Dennison S, Stjarne P, et al. Most preschool children hospitalized for acute rhinosinusitis had orbital complications, more common in the youngest and among boys. 
Acta Paediatr. 2017;106:268-73 The authors analyze pediatric patients hospitalized with ARS complications, showing that most children hospitalized for ARS had orbital complications, this being more common in boys and $<2$ years old.

65. Younis RT, Anand VK, Davidson B. The role of computed tomography and magnetic resonance imaging in patients with sinusitis with complications. Laryngoscope. 2002;112:224-9.

66. Dankbaar JW, van Bemmel AJ, Pameijer FA. Imaging findings of the orbital and intracranial complications of acute bacterial rhinosinusitis. Insights Imaging. 2015;6(5):509-18.

67. Germiller J, Monin D, Sparano A, Tom L. Intracranial complications of sinusitis in children and adolescents and their outcomes. Arch Otolaryngol Head Neck Surg. 2006;132(9):969-76.

68. Garin A, Thierry B, Leboulanger N, Blauwblomme T, Grevent D, Blanot S, et al. Pediatric sinogenic epidural and subdural empyema: the role of endoscopic sinus surgery. Int J Pediatr Otorhinolaryngol. 2015;79:1752-60.

69. Chaiyasate S, Fooanant S, Navacharoen N, Roongrotwattanasiri K, Tantilipikorn P, Patumanond J. The complications of sinusitis in a tertiary care hospital: types, patient characteristics, and outcomes. Int J Otolaryngol. 2015;2015:709302.

70. Deutschmann MW, Livingstone D, Cho JJ, Vanderkooi OG, Brookes JT. The significance of Streptococcus anginosus group in intracranial complications of pediatric rhinosinusitis. JAMA Otolaryngol Head Neck Surg. 2013;139:157-60.

71. Kou YF, Killeen D, Whittemore B, et al. Intracranial complications of acute sinusitis in children: the role of endoscopic sinus surgery. Int J Pediatr Otorhinolaryngol. 2018;110:147-51 This study investigates the role of endoscopic surgery in patients with intracranial complications and conclude that patients who underwent ESS prior to a neurosurgical procedure had significantly less risk of needing a neurosurgical intervention.
72. Bhattacharyya N. Contemporary assessment of the disease burden of sinusitis. The economic burden and symptom manifestations of chronic rhinosinusitis. Am J Rhinol Allergy. 2009;23:392-5.

73. Kennedy DW. First line management of sinusitis: a national problem? Overview. Otolaryngol Head Neck Surg. 1990;103:847-54.

74. Jaume F, Quintó L, Alobid I, Mullol J. Direct costs of acute rhinosinusitis in spain - a prospective and Observational study (Prosinus). J Investig Allergol Clin Immunol (Under revision).

75. Svensson J, Lundberg J, Olsson P, Stjärne P, Tennval GR. Costeffectiveness of mometasone furoate nasal spray in the treatment of acute rhinosinusitis. Prim Care Respir J. 2012;21(4):412-8.

76.• Cramer JD, Kern RC, Tan BK, Peters AT, Evans CT, Smith SS. Potential national savings from prescribing guidelinerecommended antibiotics for acute rhinosinusitis. Laryngoscope. 2016;26(3):579-81 This study compared the costs of antibiotic prescription for ARS in the UK, with the ideal cost when following guideline recommendations. Study results reported that current US antibiotic prescriptions for ARS account for an estimated direct cost of \$51 to \$297 million annually.

77. Piltcher OB, Kosugi EM, Sakano E, Mion O, Testa JRG, Romano FR, et al. How to avoid the inappropriate use of antibiotics in upper respiratory tract infections? A position statement from an expert panel. Braz J Otorhinolaryngol. 2018;84(3):265-79 This is a review of the most recent recommendations and guidelines for different ENT infections, including ARS, which concludes that there is a need of continuous medical education and changes in physicians' and patients' behavior to modify the paradigm that all upper respiratory infections need antibiotic therapy.

Publisher's Note Springer Nature remains neutral with regard to jurisdictional claims in published maps and institutional affiliations. 